\title{
Fractal Geometry of Seismic Clusters in the Rhodope Mountain (South Bulgaria-Northeast Greece)
}

\author{
Tzanko Tzankov ${ }^{1}$, Rosen Iliev $^{1, *}$, Svetla Stankova ${ }^{2}$, Ilia Mitkov ${ }^{1}$ \\ ${ }^{1}$ Faculty of Mathematics and Natural Sciences, South-West University "NeofitRilski", Blagoevgrad, Bulgaria \\ ${ }^{2}$ Faculty of Natural Sciences, "Konstantin Preslavsky" University, Shumen, Bulgaria
}

Copyright $\bigcirc 2018$ by authors, all rights reserved. Authors agree that this article remains permanently open access under the terms of the Creative Commons Attribution License 4.0 International License

\begin{abstract}
The Rhodope Mountain (South Bulgaria-Northeast Greece $)\left(\lambda=23.8^{\circ}-26.3^{\circ} \mathrm{E}\right.$ and $\varphi=$ $41.2^{\circ}-42.0^{\circ} \mathrm{N}$ ) is the largest mountain system in the eastern part of the Balkan Peninsula. It occupies a median position within the peninsula and thus is close enough to the main tectonic processes in this part of the Eastern Mediterranean (transcontinental collision between the African continental macro plate and Eurasian continental macro plate). This is an important prerequisite for the development of endogenous geodynamic processes with risky nature (earthquakes).The paper presents the results of the study of fractal geometry of the seismic clusters in the Rhodope Mountain. A combined seismic catalog (USGS and IRIS), composed of 640 seismic events (all values) occurring within the mountain massif for the 1965-2016 statistical period, was used in the analysis. Based on the methodology adopted for the calculation of surface fractals, the areas of the individual earthquake clusters were measured and their fractal geometry has been checked. The obtained results confirm the self-organizing nature of the seismic processes operating in the Rhodope region.
\end{abstract}

Keywords Rhodope Mountain, Earthquakes, Clusters, Fractal, Bulgaria, Greece

\section{Introduction}

The Rhodope Mountain occupies a median position within the Balkan Peninsula and thus its close enough to the main tectonic processes in the Aegean region within Eastern Mediterranean. The contemporary seismic processes in the Rhodope Mountain region is a result from the Plate tectonics processes in connection to the transcontinental collision between the continental lands of Gondwana (African continental macro plate) and Neo Europe (southern margin of the Eurasian continental macro plate) (Tzankov, Iliev, [1]). The Rhodope Mountain builds up its northern front. This determines the moderate seismic hazard in the region.

The seismic hazard for the lands of the Rhodope Mountain has average values. The earthquakes have an expected intensity to VIII-VIII ${ }^{\text {th }}$ degree according to the Medvedev-Sponheuer-Karnik intensity scale (MSK-64). Over the last decades, there have been many weak, but frequent, earthquakes in this region. For the period 1965-2016, the share of micro earthquakes $(M \leq 3)$ in the studied region amounted to $73.5 \%$ (Figure 1). Earthquakes with $\mathrm{M} \geq 4$ are only $1.5 \%$ of the total, with the strongest seismic event having a magnitude of 5.4 on the Richter scale. The average magnitude for the study period is 2.5 on the Richter scale. 


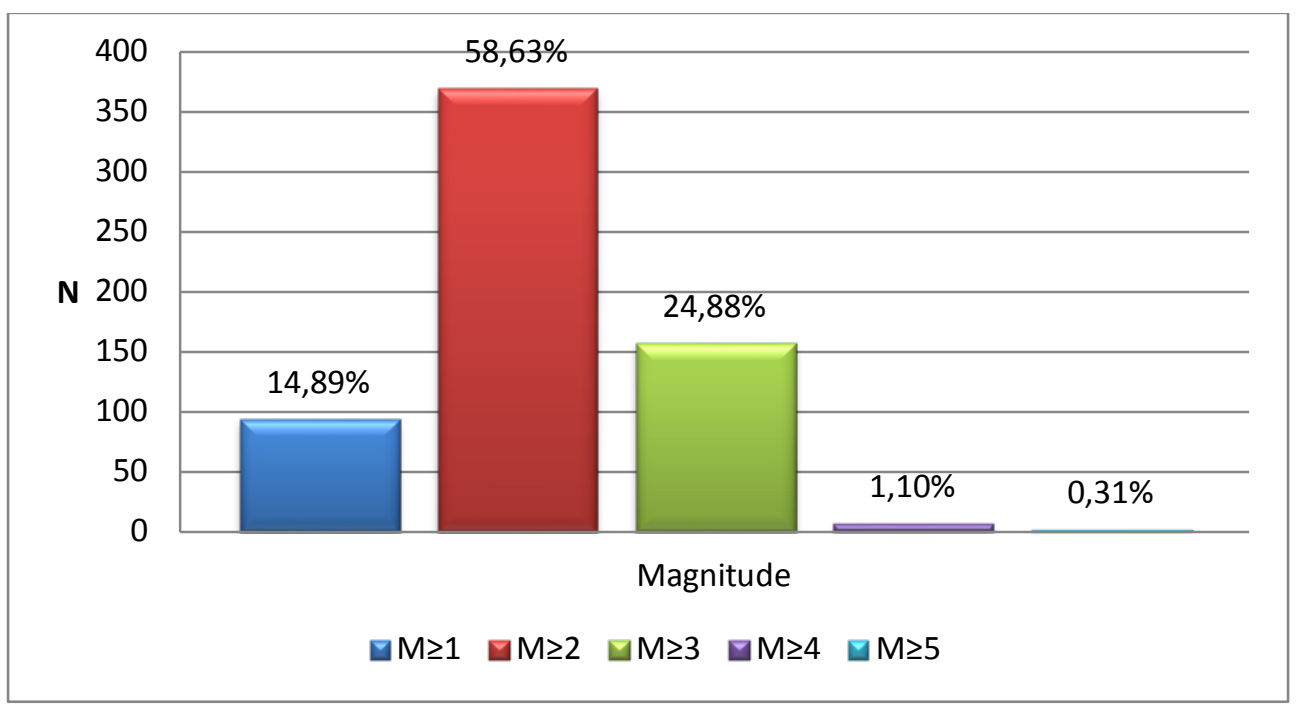

Figure 1. Distribution of earthquakes in the Rhodopes by magnitude for the period 1965-2016 (Seismic data source: [2])

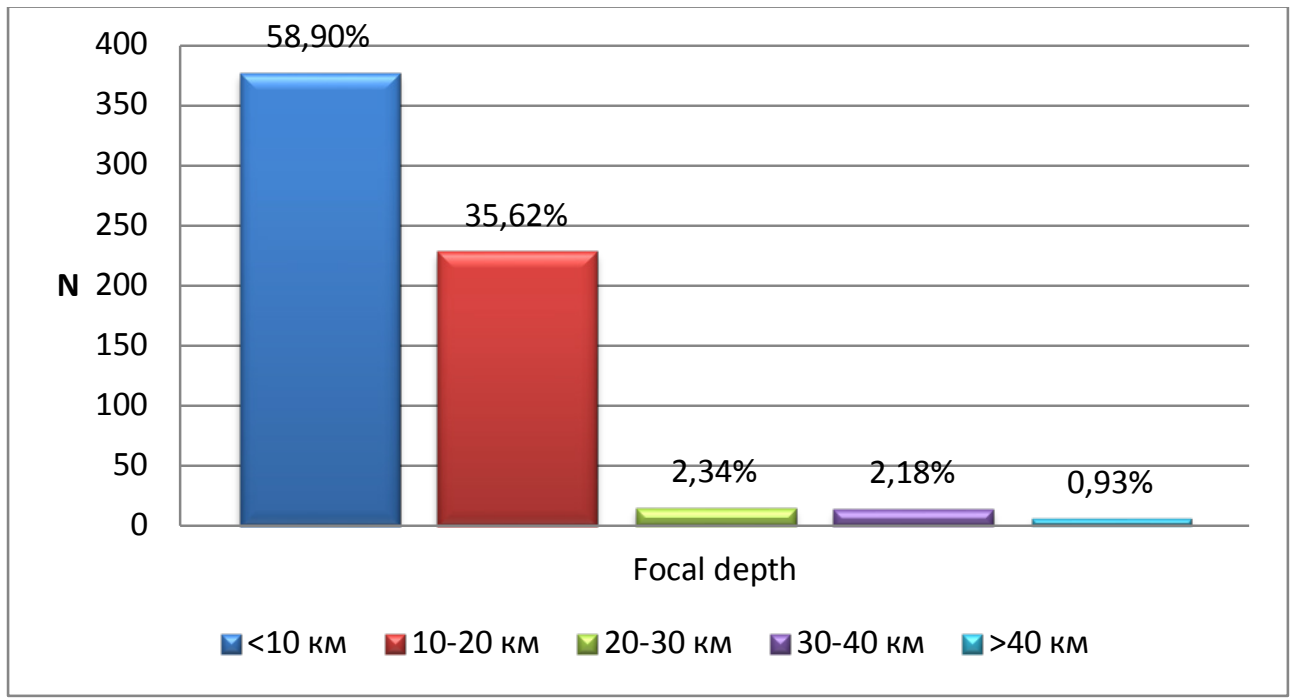

Figure 2. Distribution of earthquakes in the Rhodope Mountain by focal depth for the period 1965-2016 (Seismic data source: [2])

In the range of the Rhodope Mountain, the shallow seismic foci prevail (Figure 2). The majority of earthquakes combine low focal depth with low magnitude. For the $1965-2016$ statistical periods, $94.5 \%$ of seismic foci have a depth of up to $20 \mathrm{~km}$ (very shallow earthquakes) (Figure 2). The average focal depth is $8.2 \mathrm{~km}$.

The Rhodope seismic zone has a complex seismotectonic structure, determined by the presence of numerous active faults that serve as boundaries of the mobile Earth's crust blocks. Active in seismic terms are the fault structures along the western edge of the mountain (in the area of Kovachevitsa village, the Chepinska River, along the Middle Mesta River), in the area of Dospat-Devin and to the east along the Arda River and Varbitsa River. As can be seen from Figure 3, earthquakes in the Rhodopes are grouped into distinct seismic clusters. This predetermines the zones of the seismic energy release on the territory of the mountain massif. In spatial terms, most seismic clusters on the territory of the Rhodope Mountain are situated along the periphery. There are located the largest and most dangerous earthquake clusters. The main goal of the present study is to check and evaluate the fractal geometry of seismic clusters in the Rhodope Mountain on the basis of adopted methodology for analysis of surface fractals. This is the first study of this type at all. 


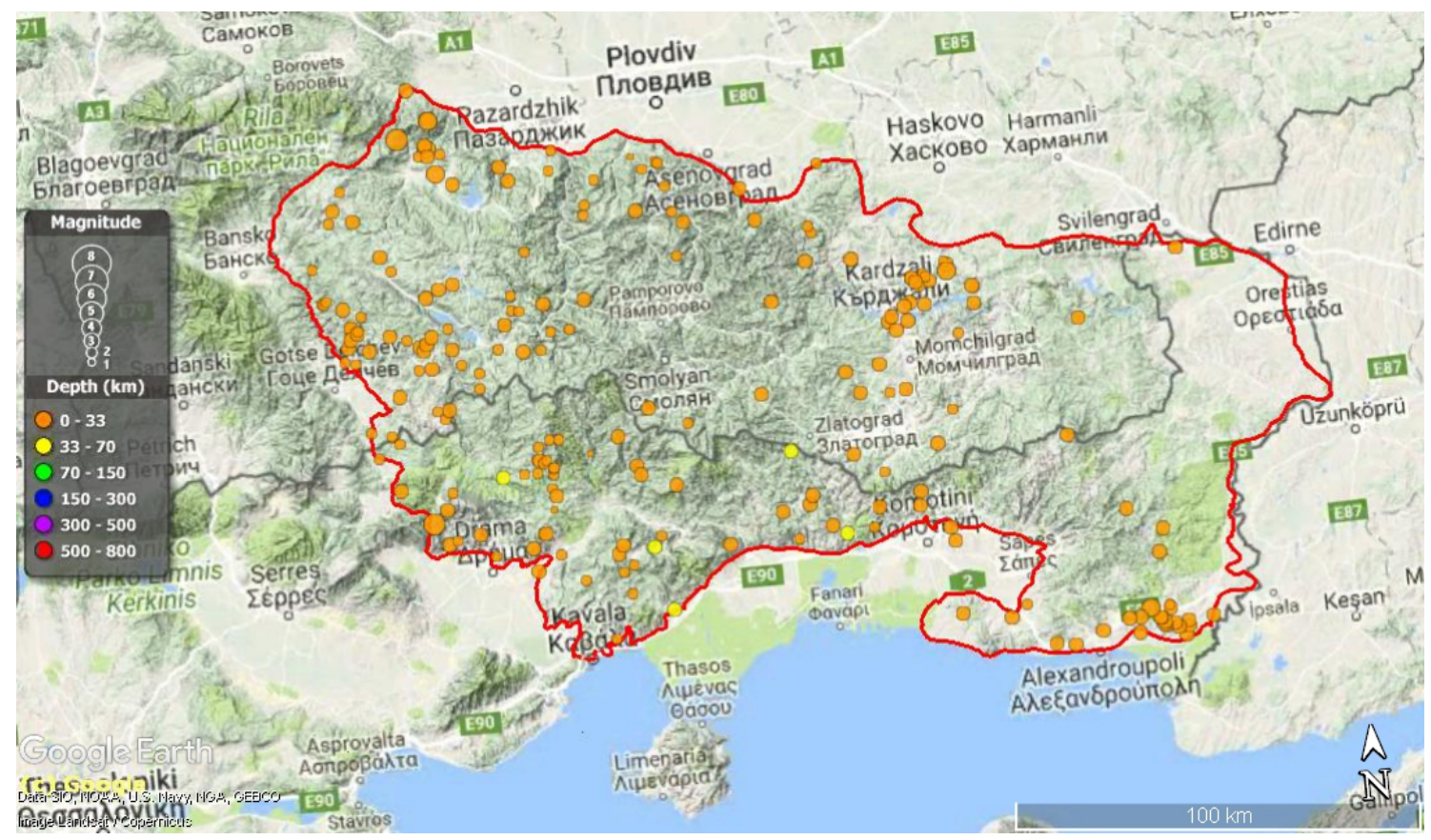

Figure 3. The earthquakes occurred in the Rhodope Mountain for the period 1965-2016 are grouped into clear seismic clusters. They are located mainly along the edges of the mountain massif. (Mapping tool: Google Earth Pro; Seismic data source: [2])

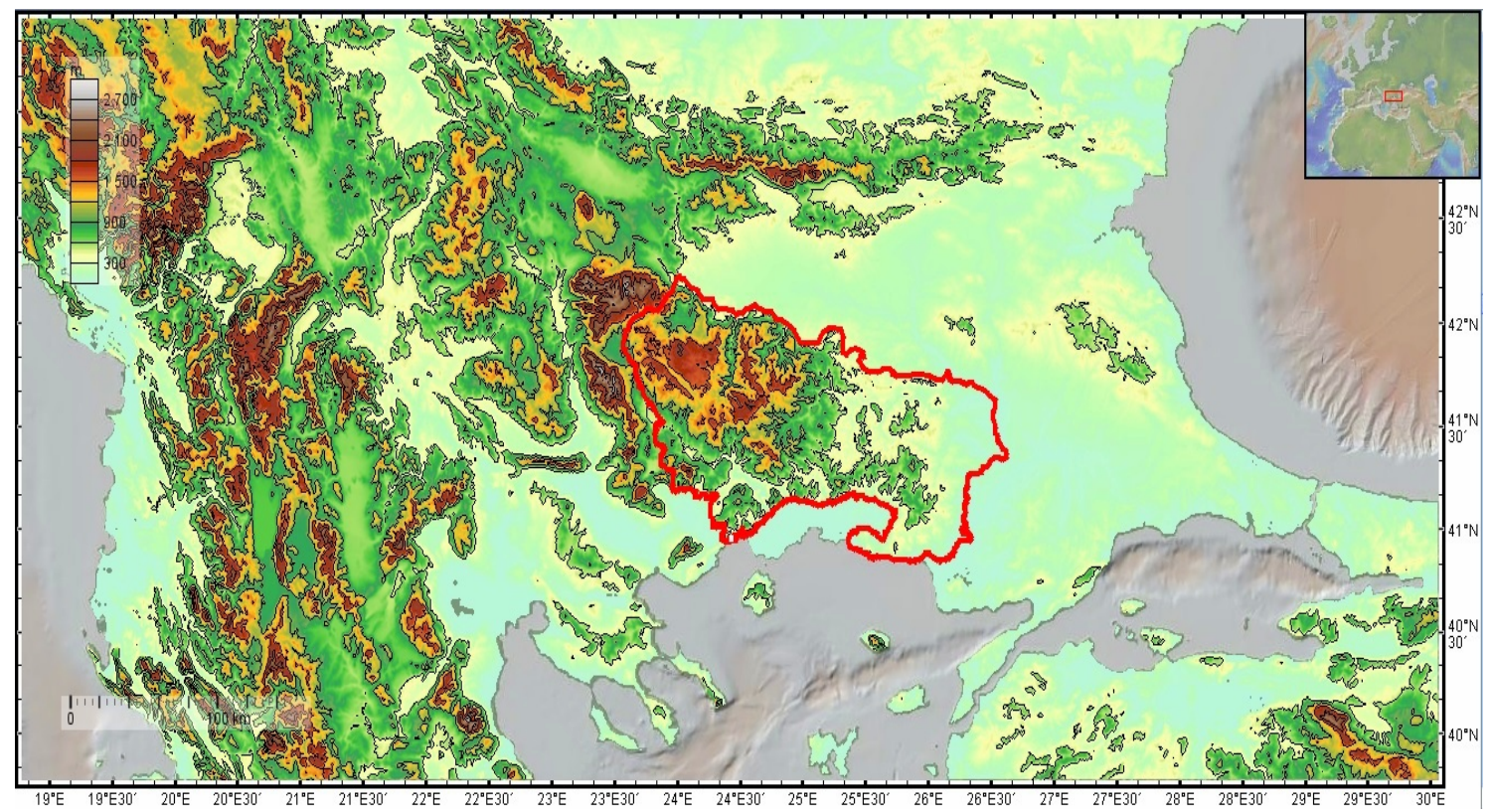

Figure 4. Survey map of the regional disposition of the Rhodope Mountain (Mapping tool: GeoMapApp-http://www.geomapapp.org)

\section{Study Area}

The Rhodope Mountain $\left(\lambda=23.8^{\circ}-26.3^{\circ} \mathrm{E}\right.$ and $\varphi=$ $\left.41.2^{\circ}-42.0^{\circ} \mathrm{N}\right)$ are the largest mountain massif in the eastern part of the Balkan Peninsula (Figure 4). It is prolonged in WNW - ESE direction at one longitude from $225 \mathrm{~km}$ by maximal width of $130 \mathrm{~km}$ within South Bulgaria and Northeast Greece. The total area of the Rhodope Mountain is about $18,000 \mathrm{~km}^{2}$, as the Bulgarian part is $14,738 \mathrm{~km}^{2}(81.88 \%$ of its entire area).

\section{Methodology and Methods}

The classical example of a fractal object is defined by Benoit Mandelbrot, [3]. If the length of an object $\mathrm{P}$ is related to the measuring unit length 1 by the formula:

$$
\mathrm{P} \sim \mathrm{I}^{1-\mathrm{D}}(1)
$$

then $\mathrm{P}$ is a fractal and $\mathrm{D}$ is a parameter defined as the fractal dimension. This definition was given by B. Mandelbrot in the early 60 -s of the 20-th century. His ideas support the view that many objects in nature cannot be described by 
simple geometric forms, and linear dimensions, but they have different levels of geometric fragmentation. It is expressed into the irregularities of the different scales (sizes) - from very small to quite big ones.

In the field of Geosciences is accepted that definition of the different «fractals» as «real physical objects is most often connected to fragmentation» (Korvin, [4]). This reveals that each measurable object has a length, surface or volume, which depends on the measuring unit and the object's form irregularity. The smaller the measuring unit is, the bigger is the total value for the linear (surface, volume) dimension of the object and vice versa. The same is valid for 2D and 3D objects (Ranguelov, [5]).

Another definition of a fractal dimension is related to the serial number of measurement to each of the measuring units used and the object dimensions. If the number of the concrete measurement with a selected linear unit is bigger than $\mathrm{r}$, then it might be presented by:

$$
\mathrm{N} \sim \mathrm{r}^{-\mathrm{D}}(2)
$$

and the fractal is completely determined by $\mathrm{D}$ as its characteristic fractal dimension. Applying this definition for the elements of faulting and faults fragmentation, some authors use this idea to depict formal models of the Earth's crust fragmentation, which indicates the level of fracturing of the upper Earth's layers (Ranguelov, Dimitrova, [6]; Ranguelov, Ivanov, [7]).

The methodology based on the correlation number-area (surface fractals) is following the algorithm presented and effectively applied in a number of publications (Meyback, [8]; Ranguelov et al., [9], [10]; Ranguelov, [5], [7]):

- presentation of the data for each selected element (total number, investigated parameter, dimensions - (only linear (1D) and surface sizes (2D) are considered)
- calculation of the number for the graphics (selection of the calculation step for $\mathrm{X}$ and $\mathrm{Y}$ axes, scale on $\mathrm{X}$ and $\mathrm{Y}$ axes, values for each selected parameter).

- presentation of the results on the graphics - on the $X$ axis the semi-logarithmic scale is most convenient, on the $\mathrm{Y}$ axis, $\mathrm{z}$ denotes in linear scale the numbers calculated for each element.

The present study examines the seismic clusters in the Rhodope Mountain as surface objects and applies the abovementioned methodology to them. The research is based on 38 seismic clusters. Approximately 640 earthquakes (all values) occurred during the period 1965-2016 on the territory of the Rhodope Mountain are included. Their data is collected in a combined seismic catalog created on the basis of free earthquake catalogs of USGS (United States Geological Survey) Seismic Hazard Program [2] and IRIS (Incorporated Research Institutions for Seismology) [11]. Seismic clusters are defined as areas of 3 or more earthquake epicenters. The area of these earthquake clusters is calculated using a modern, interactive GIS software product. This provides the necessary methodological basis for measuring the area of seismic clusters in other regions, which creates prerequisites in the future for different comparative studies on this basis.

\section{Results and Discussion}

The results from the analysis of fractal geometry of the seismic clusters in the Rhodope Mountain are presented in graphical form in Figure 5.

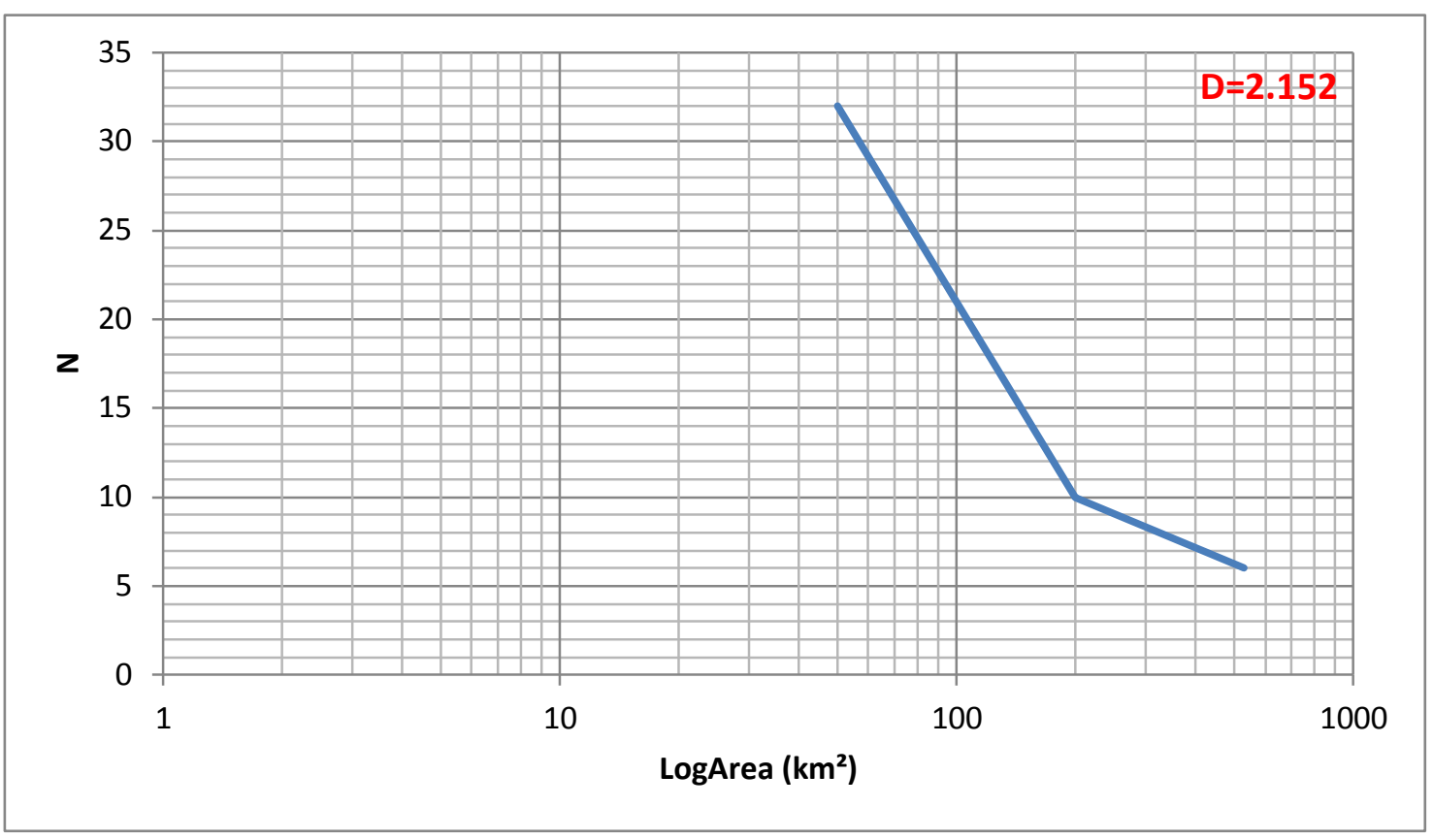

Figure 5. Fractal analysis of the seismic clusters in the Rhodope Mountain with calculated fractal dimension 
As shown in Figure 5, spatial grouping of seismic events on the territory of the Rhodope Mountain is essentially fractal. This shows that the release of the seismic energy in the Rhodope mountain massif have a strict mathematical conditionality. According to the principles of self-organization seismic energy within the Rhodope Mountain is released into territories with different scale invariance (fractality). The estimated fractal dimension (D $=2.152$ ) indicates that seismic clusters are characterized by a relatively high level of fragmentation. It is the most favorable form of reorganization of the seismic process to release the energy in multiple places, not one or two. This prevents catastrophic processes and controls the amount of energy emitted, which is why the most severe seismic phenomena in the Rhodope Mountain historically have occurred along the periphery of the mountain massif. The distribution of the earthquake phenomena along the periphery is explained by the fact that the accumulated seismic energy can easily and unimpeded be released in a low-resistance environment. Starting from the Fermat principle, seismic energy travels from point A (hypocenter) to point $B$ (the place of release of the energy of the surface), following the path that travels in the shortest time. This basic principle of geometric optics explains why the boundary parts of the huge mountain massif like the Rhodopes are best suited for separating accumulated tectonic stresses.

Generally, the results obtained can be summarized as follows:

1) The micro-earthquakes dominate the territory of the Rhodopes ( $73.5 \%$ of all cases). The stronger earthquakes $(\mathrm{M} \geq 4)$ are rare.

2) The seismic process is developing at a shallow depth, with nearly $95 \%$ of the earthquakes having a focal depth of up to $20 \mathrm{~km}$. There is no seismic phenomenon deeper than $47 \mathrm{~km}$. This clearly shows the crustal nature of seismic processes in the area.

3) The earthquakes in the Rhodope Mountain occur mainly on the edges of the mountain massif. There are also recorded the strongest seismic events historically.

4) Earthquakes in the Rhodope Mountain are grouped into seismic clusters that have clear fractal geometry. Spatial fragmentation of seismic events grouping is combined with low energy and low focal depth of the earthquakes. This clearly demonstrates the self-organizing nature of the seismic processes in the Rhodope region.

\section{Conclusions}

The results of the conducted research unequivocally confirmed the fractal geometry of seismic clusters on the territory of the Rhodope mountain massif. This sets out the principles of releasing of the seismic energy in this area. On the other hand conducted results serves as solid evidence of the self-organizing nature of endogenous processes in the region of the Rhodope Mountain. The discovered fractal properties of seismic clusters suggested that there is synergy in the principles of development of seismic processes in the region. It offers deeper understanding for the Earth's geodynamic processes.

The fractal analysis applied in the present study is an indispensable mathematical tool for assessing and verifying the degree of self-organization of seismic processes not just for the Rhodope region, but also in general. With his help, a better interpretation of the principles of separation of seismic energy was possible. In view of the pioneering nature of the present study, the results obtained in the future can become a good basis for different correlation studies at the regional level. A leading role in this could be the present study of fractal geometry of seismic clusters in the Rhodope Mountain.

\section{REFERENCES}

[1] TzankovTz., Iliev R. Morphostructure of the Rhodopean mountain massif. Publishing House "Grafika 19", Sofia, Bulgaria, 2015, $48 \mathrm{p}$.

[2] USGS Seismic hazard program, Online available from https://earthquake.usgs.gov/earthquakes/search/

[3] Mandelbrot B. The fractal geometry of nature, San Francisco, W.H. Freeman \& Co., 1982, 368 p.

[4] Korvin G. Fractal models in the Earth Sciences. Elsevier Press, New York, 1992, 236 p.

[5] Ranguelov B. Nonlinearities and fractal properties of the European-Mediterranean seismotectonic model. In: Geodynamics \& Tectonophysics, V.1, № 3, 2010, 225-230.

[6] Ranguelov B., Dimitrova S. Fractal model of the recent surface earth crust fragmentation in Bulgaria. In: Comptes Rendus de l'Academy Sciences Bulgaria, V. 55, № 3, 2002, $25-28$

[7] Ranguelov B., Ivanov Y. Fractal properties of the elements of Plate tectonics. In: Journal of mining and Geological Sciences. Vol. 60, Part 1, Geology and Geophysics, 2017, 83-89

[8] Meybeck M. Global distribution of lakes. In: Lerman, A., Imboden, D.M., Gat, J.R. (Eds.), Physics and Chemistry of Lakes, 2nd ed., Springer-Verlag, Berlin, 1995, 1-35

[9] Ranguelov B., Dimitrova S., Gospodinov D. Fractal configuration of the Balkan seismotectonic model for seismic hazard assessment. Proceedings BPU-5, Vrnjacka Banja, Serbia and Montenegro, 2003, 1377-1380

[10] Ranguelov B., Dimitrova S.,Gospodinov D., Spassov E., Lamykina G., Papadimitriou E., Karakostas V. Fractal properties of the South Balkans seismotectonic model for seismic hazard assessment. Proceedings 5th Intl. Symposium on East Mediterranean Geology, Thessalonica, 2004, 643-646

[11] Iris Earthquake Browser, Online available from http:// www.iris.edu/hq/ 